
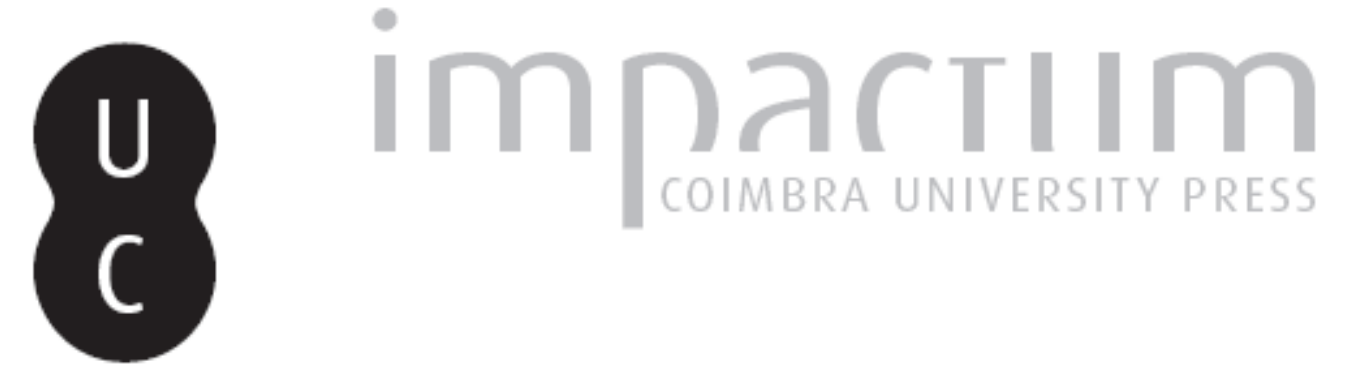

\title{
Conhecimento histórico e historiografia brasileira contemporânea
}

Autor(es): $\quad$ Martins, Estevão de Rezende Publicado por: $\begin{aligned} & \text { Faculdade de Letras da Universidade de Coimbra, Instituto de História } \\ & \text { Económica e Social }\end{aligned}$

URL

persistente:

URI:http://hdl.handle.net/10316.2/27928

DOI:

DOI:http://dx.doi.org/10.14195/0870-4147_42_9

Accessed : $\quad$ 26-Apr-2023 12:57:43

A navegação consulta e descarregamento dos títulos inseridos nas Bibliotecas Digitais UC Digitalis, UC Pombalina e UC Impactum, pressupõem a aceitação plena e sem reservas dos Termos e Condições de Uso destas Bibliotecas Digitais, disponíveis em https://digitalis.uc.pt/pt-pt/termos.

Conforme exposto nos referidos Termos e Condições de Uso, o descarregamento de títulos de acesso restrito requer uma licença válida de autorização devendo o utilizador aceder ao(s) documento(s) a partir de um endereço de IP da instituição detentora da supramencionada licença.

Ao utilizador é apenas permitido o descarregamento para uso pessoal, pelo que o emprego do(s) título(s) descarregado(s) para outro fim, designadamente comercial, carece de autorização do respetivo autor ou editor da obra.

Na medida em que todas as obras da UC Digitalis se encontram protegidas pelo Código do Direito de Autor e Direitos Conexos e demais legislação aplicável, toda a cópia, parcial ou total, deste documento, nos casos em que é legalmente admitida, deverá conter ou fazer-se acompanhar por este aviso.

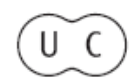





\title{
Conhecimento histórico e historiografia brasileira contemporânea
}

\author{
Estevão de ReZende Martins \\ Professor titular de Teoria da História e História Contemporânea na Universidade de Brasília \\ Presidente da Sociedade Brasileira de Teoria e História da Historiografia \\ ecrm@terra.com.br
}

\section{Resumo:}

O debate sobre o sentido e a função do conhecimento histórico parece sempre ocorrer contra o pano de fundo teórico e prático que, a cada nova geração, a cada novo impacto da transformação social e cultural, requer haver-se com a experiência do tempo e do agir vividos. O uso indistinto do termo História na língua portuguesa (como em outras) aconselha que se busque esclarecer sua polissemia. Propõe-se a sistematização de seus quatro sentidos: história-processo, história-consciência, história-ciênca, história-historiografia. Estabelecidos os pressupostos gnosiológicos e epistemológicos, recorre-se ao terceiro e ao quarto sentido para discorrer sobre o itinerário da historiografia produzida no e sobre o Brasil, especialmente na segunda metade do século 20. Expõe-se as principais etapas desse percurso: a dos desbravadores (notadamente século 19), a dos pioneiros (até meados do século 20) e a dos profissionais (da segunda metade do século 20 em diante). Exemplifica-se com temas, concentrações, objetos, plataformas de pesquisa e publicação contemporâneos.

\section{Palavras chave:}

Teoria da história; Conhecimento histórico; Historiografia brasileira.

\section{Abstract:}

The debate about the meaning and function of historical knowledge always seems to occur in the context of the theoretical and practical background that, at each new generation and at every impact of social and cultural transformation, requires to be challenged by the experience of time and living action. The indefinite use of the word History in Portuguese, as in other languages, suggests that its polysemy must be clarified. A proposal is made to organize the four meanings of the term: history-process, history-consciousness, history-science, history-historiography. Once the gnosiological and epistemological assumptions have been established, we proceeded to the third and fourth senses in order to discuss the course of Brazilian historiography, specially in the second half of the $20^{\text {th }}$ century. The main stages of this itinerary are then specified: the trailblazers (namely in the $19^{\text {th }}$ century); the pioneers (up to the middle $20^{\text {th }}$ century); the professionals (from the second half of the $20^{\text {th }}$ century on). Several examples are given of topics, central matters, objects, research grounds and contemporary publications.

Keywords:

Theory of History; Historical knowledge; Brazilian historiography. 


\section{Preliminares}

O uso indistinto do termo História na língua portuguesa (como em outras) aconselha que se busque esclarecer os sentidos que possui. A polissemia da "história" é um truísmo. Justamente por isso é razoável convencionar com que sentido se está lidando aqui. Pode-se distinguir ao menos quatro usos correntes. Que conceitos estão presentes nesse uso? O primeiro é o mais genérico e impreciso: chama-se de História o conjunto (mesmo elementos presentemente desconhecidos) da existência humana no tempo, mesmo se não se sabe quando haja começado ou quando há de terminar. Nesse sentido, História recobre qualquer ação humana e é nesse contexto que se fala, mais comumente, do "curso da história".

O segundo sentido introduz uma circunscrição conceitual. História diz respeito à memória consciente daqueles agentes e daquelas ações que qualificam a identidade pessoal e social dos integrantes de uma dada comunidade. Crônica da especificidade, essa história continua sendo, contudo, um registro amplo do agir no tempo, restrito dessa feita a uma sociedade particular. Não raro esse tipo de registro memorial da glória (ou da pretensão de eminência) está carregado de elementos ditos "civilizacionais", de cunho sobretudo político.

Um terceiro sentido introduz uma restrição mais técnica. É a História enquanto conhecimento controlável e demonstrável, chamada de científica, ou ciência da história. Essa última expressão encerra ainda certa duplicidade, na medida em que mantém o pressuposto dos dois primeiros sentidos (uma História cientificamente cognoscível e explicável, mais ampla do que a metodicamente restringida), como sua base empírica suposta.

O padrão de cientificidade que se aplica é, por certo, o modelo do racionalismo moderno, cartesiano ou empirista, acentuadamente marcado pelo sucesso - mesmo que tido cada vez mais como relativo - das ciências ditas experimentais.

O quarto sentido é o que recorre ao termo "História" para designar as narrativas (de todos os tipos) com que se relata o agir passado dos homens no tempo. Com respeito aos dois primeiros sentidos, o "vou contar como foi essa história" inclui uma grande variedade de formas literárias do falar e do escrever. ${ }^{1}$

Crônicas, fábulas, contos, tradições orais, memórias, anais, enfim uma legião de possibilidades que, ao se apresentarem como "história", mesmo se não satisfazem o contrato metódico das pesquisas científicas, servem-lhes de

1 Margareth Rago e Renato A. de O. Gimenes (eds.): Narrar o passado, repensar a história. Campinas: Unicamp, 2000. 
fonte. No caso do entendimento da História como uma disciplina metódica de pesquisa, com resultados intersubjetivamente controláveis (terceiro sentido), aplica-se, para o produto narrativo acabado, o termo, algo mais técnico, de historiografia. Trata-se do "livro de História" de que se fala quando tema, autor e forma metódica de tratamento do assunto ensejam determinado grau de confiabilidade somente efetivado na História como ciência.

Como se trata de conceitos construídos - mesmo se não arbitrariamente, mas sem dúvida de modo convencional - é útil, para o estudioso, entender e reconstituir o caminho percorrido, no debate acadêmico e historiográfico, pelos autores e pelos textos que balizaram o debate e as maneiras pelas quais esses entendimentos foram sendo distinguidos e consolidados.

Há ainda uma grande rede de interrelações entre o que faz a História como ciência e as reflexões da filosofia, da sociologia, da antropologia, da psicologia - enfim, das ciências humanas e sociais. Questões com relação à verdade, à aptidão a conhecer, à demonstrabilidade de asserções, à relatividade subjetiva e social das narrativas, ao caráter lacunar das bases empíricas de informação, à relevância do saber histórico para a vida prática e assim por diante, pertencem ao quotidiano do fazer histórico e da busca de sua plausibilidade. ${ }^{2}$

\section{Conhecimento histórico: sentido e função}

O debate sobre o sentido e a função do conhecimento histórico parece sempre ocorrer contra o pano de fundo teórico e prático que, a cada nova geração, a cada novo impacto da transformação social e cultural, requer haver-se com a experiência do tempo e do agir vividos. Os autores de que se fala mais adiante lidam com contextos formais de técnicas de pesquisa e de formação profissional tanto quanto com missões patrióticas de constituição da nacionalidade ou do Estado. Flertam com a elegância estilística e o convencimento retórico, com a sedução da palavra ou da imagem. Ilustram, pois, por quantos caminhos começou o esforço de dar à História como ciência, suas credenciais de nobreza acadêmica, de confiabilidade metódica, de plausibilidade argumentativa, de relevância político-social e cultural. Estão eles conscientes da fragilidade

2 Ciro Flamarion Cardoso e Héctor Perez Brignoli. Os métodos da história. Rio de Janeiro: Graal, 1981, 2a ed.; Ciro Flamarion Cardoso e Ronaldo Vainfas (eds.). Domínios da história: ensaios de teoria e metodologia. Rio de Janeiro: Campus, 1997. 
relativa das conclusões entretecidas nas narrativas, pois a cada tempo corresponde sociabilidade, sensibilidade e objetividade relacionais ${ }^{3}$.

Como as ciências sociais em geral, a historiografia passou por um processo extraordinário de transformação depois da Segunda Guerra Mundial. É possível que o impulso não tenha bastado para gerar o que o historiador alemão Jörn Rüsen chamou de "matriz disciplinar" uniforme. Mas há claros indícios de um modelo básico fortemente difundido, cujo efeito foi indispensável ao progresso global da historiografia como investigação social auto-suficiente e coesa e ainda o é para sua compreensão. ${ }^{4}$ A ciência histórica conheceu, na segunda metade do século 20 , um avanço prodigioso: renovação, enriquecimento das técnicas e dos métodos, dos horizontes e dos domínios. A presente reflexão se centra primordialmente na "época de ouro" que representou o salto qualitativo operado na segunda metade do século 20 e entra pelo século 21 . Embora não se possa afirmar que a história seja disciplina recente, os contornos que assumiu, nas duas fases decisivas do século 20, nos anos 20-30 e a partir dos anos 50, constituem uma renovação e mesmo uma redefinição contemporânea ${ }^{5}$.

A importância transcendental do século 19 para os fundamentos da disciplina da historiografia em seu estado atual se deve a um fenômeno único, de desdobramentos complexos: o abandono das concepções relativas à investigação e à escrita da história que formaram a tradição europeia praticamente desde o Renascimento e talvez mesmo desde a Antiguidade clássica. As diversas escolas e correntes historiográficas do século 19 coincidem pelo menos em um ponto: deixam de considerar a história como uma crônica baseada nos testemunhos legados pelas gerações anteriores e entendem-na como uma investigação, pelo que o termo "história" recupera seu sentido originário em grego. ${ }^{6}$

A evolução decisiva para a historiografia se dá com o que se pode chamar de fundamentação metódico-documental, basilar para a disciplina "acadêmica" contemporânea, produzida pelos tratadistas do século 19 e da primeira década do século 20. Tem-se aqui a origem da grande corrente historiográfica que

3 E. de Rezende Martins. O caráter relacional do conhecimento histórico. In Cléria Botelho da Costa (ed.). Um passeio com Clio. Brasília: Paralelo 15, 2002, p. 11-25.

4 Jörn Rüsen: Historik. Vol. 1: Razão histórica (1983). Brasília: Editora Universidade de Brasília, 2001; Vol. 2: Reconstrução do Passado (1986). Brasília: Editora da Universidade de Brasília, 2007; Vol. 3: História Viva (1989). Brasília: Editora da Universidade de Brasília, 2007.

5 O primeiro grande balanço 'clássico' dos caminhos da história no século 20 está em Charles Samaran (org.): L'Histoire et ses méthodes. Paris: La Pléiade, 1961. Cf. também: Ch.-O. Carbonnell e Jean Walch (orgs.): Les sciences historiques de l'Antiquité à nos jours. Paris: Larousse, 1994.

6 J.Malerba (ed.). A história escrita; teoria e história da historiografia. São Paulo: Contexto, 2006. 
se chamou - de forma algo exagerada, mas não totalmente imprópria - de historiografia positivista, intimamente entrelaçada com a forte tradição do historicismo alemão. É no século 19 que aparecem os primeiros grandes tratados do que se poderia chamar de normativismo histórico, um tipo de reflexão novo sobre a história, chamado de Historik por Johann Droysen. Essa reflexão define os parâmetros metódicos estipulados como obrigatórios para que a história se enquadre no que se tinha, então, por padrão de "ciência". Essa a razão pela qual esses tratadistas tomam como referência específica do estudo de história a ciência natural. Esse normativismo leva à produção de textos metodológicos famosos, sobretudo na França e na Alemanha, de Buchez e Lacombe, de Ranke, de Droysen e de Bernheim, chegando a Langlois-Seignobos e a Lamprecht. ${ }^{7}$

Que pertinência objetiva possui a história, atualmente, na era do excesso de dados, informações, pontos de vista? ${ }^{8}$ A questão da verdade "na" história e "sobre" a história continua primordial, inclusive no plano da análise do discurso. A busca da verdade, da objetividade, mesmo se sob as múltiplas condições da pesquisa superabundante, permanece como uma das especificidades do discurso histórico, em contraste com a pretensão - descomprometida - de uma história-ficção. Na historiografia de hoje como na mais antiga, nada menos problemático do que essa questão. O que não é pouco, pois - com a abundância e a variedade das fontes - há, por assim dizer, mais "história" do que antes. ${ }^{9}$

Sem dúvida uma das empresas mais fecundas e das mais renovadoras da historiografia contemporânea foi a da história social. Ainda não é possível avaliar até que ponto essa tendência constitui novo modelo ou paradigma historiográfico. ${ }^{10}$ Seu impulso vai além da história social setorial e apresenta uma nova prática de pesquisa e de síntese. Sua dependência da sociologia histórica no estilo de T. Skocpol ${ }^{11}$ está evidenciada nos trabalhos de C. Tilly, M. Mandelbaum, A. Giddens, R. Harré e outros. Trata-se de uma corrente que se diferencia da proposta, certamente influente, de Jean Walch, de uma historiografia estrutural, muito mais próxima da sociologia do que da historiografia.

7 E. de Rezende Martins (ed.). A História pensada. Teoria e metodologia na historiografia europeia do século XIX. São Paulo: Contexto, 2010.

8 Thomas Nipperdey: Pode a história ser objetiva? Manuscrito de 1983, trad. de E. de Rezende Martins.

9 J. Malerba (ed.). Lições de História: o caminho da ciência no longo século XIX. Rio de Janeiro/Porto Alegre: Editora FGV/EdiPucrs, 2010.

${ }^{10}$ J. Malerba; C. A. Aguirre Rojas (eds.). Historiografia contemporânea em perspectiva crítica. Bauru, SP: EDUSC, 2007.

${ }^{11}$ Theda Skocpol: Estados e revoluções sociais: análise comparativa da França, Rússia e China. Lisboa: Editorial Presença, 1985. 
No início do século 21, tem-se que a história consolidou dois grandes traços de seu perfil. O primeiro é a vitória sobre o ceticismo metódico do início do século 20, que somente aceitava como científico o conhecimento que copiasse o modelo das ciências naturais. A história, ao longo do século 20, tornou-se, indiscutivelmente, ciência histórica. Seus procedimentos metódicos, suas práticas de pesquisa e seus resultados satisfazem aos critérios de confiabilidade, verossimilhança e controlabilidade. Seu produto - a historiografia - submete-se ao crivo intersubjetivo da comunidade profissional. Para alcançar esse grau de desenvolvimento epistêmico a história elaborou e articulou a fundamentação teórica e metodológica de seu caráter argumentativo e demonstrativo. O segundo traço está na circunstância de que o conhecimento e a ciência histórica aplicam-se a toda e qualquer ação humana, individual ou coletiva. Ciência do tempo, a história é um componente indispensável de toda a atividade temporal. O século 20 confortou o historiador na tarefa de transformar a história (res gestae) de fardo - como dizia Hegel - em uma história rerum gestarum que faça do conhecimento do passado um instrumento de emancipação intelectual e cultural. ${ }^{12}$

\section{Historiografia brasileira contemporânea}

A reflexão histórica fundante, própria à elaboração do substrato identitário de uma sociedade e de sua organização social e cultural ao longo do tempo, habitualmente chamada de "história nacional", dá-se obviamente também no Brasil.

A historiografia brasileira contemporânea abarca pelo menos dois grandes grupos de investigações: um, genérico, diz respeito à história escrita no Brasil e desde suas perspectivas de interesse e análise; outro, específico, relativo à história que tem o Brasil, de uma ou outra forma, como objeto. Neste segundo grupo está incluída a historiografia dita "brasilianista", produzida sobretudo fora do país, notadamente nos Estados Unidos e na Europa. O grupo que interessa à presente reflexão é o primeiro.

Desde os anos 1970 o crescimento da pesquisa histórica no Brasil tornou-se exponencial. Esse crescimento vem acompanhado de outro, o do interesse, no espaço público, por temas históricos e por seu tratamento historiográfico.

Quase cinquenta anos de avanços notáveis na apropriação sistemática das fontes para a história do Brasil, na internacionalização dos temas e das perspectivas, na expansão global de estudos no Brasil e sobre ele, na contextua-

\footnotetext{
${ }^{12}$ Roberto Forastieri da Silva. História da Historiografia. São Paulo: Edusc, 2011.
} 
lização sistêmica do pensamento, da consciência e da cultura históricas tiveram suas etapas prévias.

José Roberto do Amaral Lapa (1929-2000) publicou em 1982, na Revista Brasileira de História, interessante artigo sobre as "tendências atuais da historiografia brasileira". ${ }^{13}$ Buscava inventariar, com base nomeadamente em dados do Arquivo Nacional, que perfil adquiria a investigação histórica no Brasil e em que volume de publicações se exprimia. Orientou sua pesquisa por seis questões elementares, cuja pertinência continua válida: (1) "Em que direções se projeta o conhecimento histórico brasileiro? (2) O que caracteriza esse conhecimento como ciência? (3) Em que níveis se desenvolvem suas progressões? (4) Os historiadores que os produzem estão vocacionalmente voltados para que períodos da História do Brasil? (5) Quais as especializações que têm recebido maior escolha? (6) E dentro delas quais os temas que mais vêm sido contemplados e a partir de que abordagens metodológicas?"

Percebe-se que Amaral Lapa recorre a três quesitos de cunho teórico-metodológico (as perguntas 2, 3 e a segunda parte da 6), o que revela uma preocupação tempestiva, já à época, com a reflexão sobre fundamentos, o que ainda não era corrente na comunidade de historiadores. Outros três quesitos articulam-se explicitamente em torno de uma espécie de 'brasilidade': a adjetivação de conhecimento histórico como 'brasileiro', os níveis de seu progresso, a 'vocação' para períodos, as especializações escolhidas. Amaral Lapa dá voz a um programa de sistematização que, gradualmente, vem a ganhar espaço na produção historiográfica brasileira, logo após a década de $1980 .{ }^{14}$ Marca com isso 'etapas' da reflexão histórica no país, acerca das quais uma palavra é oportuna.

As etapas de instituição, crescimento e consolidação do campo historiográfico consistem na fase dos desbravadores, na dos pioneiros, na da profissionalização e na da expansão. A primeira, dos desbravadores, se concentra no século 19, mas inclui autores e obras anteriores. A segunda, a dos pioneiros, vem do final do século 19 e alcança até a década de 1930. A terceira, a da profissionalização, vem de finais da década de 1930 e se estende até meados da década de 1970. A da expansão recobre o período desde então até os dias atuais.

Chama-se de desbravadores os autores de uma geração que, sem específica prática historiográfica formal, como de praxe nos séculos 18 e 19, toma temas de história como objeto de sua reflexão e os coloca como objetivo de

${ }^{13}$ R. bras. Hist., São Paulo, 2 (1982), p. 153-172.

${ }^{14}$ José Roberto do Amaral Lapa. Historiografia brasileira contemporânea. Petrópolis: Vozes, 1981, 2a ed. 
suas explanações. Inicialmente inseridos em questões relativas ao conjunto do império português, os assuntos 'brasileiros' emancipam-se, tornando-se gradualmente matéria de investigação e análise próprias. O estabelecimento da sede do império no Rio de Janeiro e, posteriormente, a independência do Brasil em 1822 estipulam marcos temporais que incentivam a busca de sentido e orientação para o fato histórico que modifica as condições de ser e agir no país.

Francisco Iglésias, sem a qualificar tematicamente, deixou uma proposta de periodização por datas: a) 1500 a 1838 - dos primórdios até a criação do Instituto Histórico e Geográfico Brasileiro; b) 1838 a 1931 - do IHGB à reforma do sistema de ensino elaborada por Francisco Campos e decretada por Getúlio Vargas; c) 1931 a nossos dias (Iglésias faleceu em 1999 e suas anotações levam em conta ainda parte da década de 1990). A preocupação abrangente de Iglésias, diferente daquela de Amaral Lapa, tem seu fundamento na lógica de recuperação da totalidade de toda e qualquer obra que, por sua natureza, interesse e seja útil à produção de uma história do Brasil. Preocupação análoga se encontra na obra monumental do crítico literário Wilson Martins (1921-2010), cuja História da Inteligência Brasileira cobre o período de 1550 a $1960 . .^{15}$

\subsection{Os desbravadores}

Pode-se chamar assim àqueles que, no século dezenove e nas quatro primeiras décadas do século 20, desbravaram as sendas da pesquisa histórica, tanto na coleta e organização das fontes quanto no pensamento sobre 'quem' ou 'o quê' é o Brasil. Essa questão foi inaugurada, por assim, dizer no famoso concurso de 1840 do Instituto Histórico e Geográfico Brasileiro (fundado em 1838), em que foi premiado um alemão Carl von Martius, com a monografia "Como se deve escrever a história do Brasil". ${ }^{16}$

Alguns grandes personagens do século 19 dedicaram-se pois ao trabalho inaugural, por isso desbravador, de enfrentar a tarefa de definir o 'Brasil' e estipular-lhe uma história. Ainda antes do escrito programático de von Martius, que respondia a uma instigação explícita do Brasil já independente, a obra de um outro não brasileiro se dedicara à tarefa de decifrar esse novo mundo: a History of Brazil, do poeta inglês Robert Southey. ${ }^{17}$ Southey escreve uma

${ }^{15}$ Reedição: Ponta Grossa: Editora da Universidade Estadual de Ponta Grossa, 2010, 7 vols . Edição original: São Paulo: Cultrix/EdUSP, 1976-1978.

${ }^{16}$ Como se deve escrever a História do Brasil, publicado com O Estado de Direito entre os autóctones do Brasil. Belo Horizonte/São Paulo, Itatiaia/EDUSP, 1982

${ }^{17}$ Robert Southey. History of Brazil. Londres: Longman, Hurst, Rees and Orme, 1810 e 1819 . 
história a priori, fundada em conhecimentos livrescos e marcada pelas convicções políticas de um britânico esclarecido da virada do setecentos para o oitocentos.

É ao visconde de Porto Seguro, Francisco Adolfo de Varnhagen (1816-1878), contudo, que advém o mérito de ter iniciado, à maneira de Ranke e de Droysen, o trabalho de coleta e sistematização das fontes indispensáveis à qualificação da pesquisa histórica como 'brasileira', mesmo se de forma incipiente. ${ }^{18}$ Foi-lhe utilíssima, nessa atividade, sua condição de diplomata, em posto na América latina e na Europa. Conservador e monarquista convicto, Varnhagen - no dizer de Francisco Iglésias - "é desses autores que provocam admiração pelo vulto de seu trabalho, mas jamais fascinam". ${ }^{19}$

O século 19 ainda é testemunha de outros desbravadores, dedicados à celebração dos feitos regionais, como os de Pernambuco, Pará e Minas Gerais, por exemplo. ${ }^{20}$ Esses exemplos não são únicos. Uma verdadeira rede de pesquisadores, ativos jornalistas ou juristas, seguidores da metodologia de Varnhagen, coletam e sistematizam fontes. Tal preocupação segue ininterrupta, até os dias de hoje, para uma historiografia brasileira que, em substancial parte de seu fazer, depende de arquivos situados em outros países, sob diferentes pontos de vista. Ensaios de abrangência geral, no entanto, restringem-se às obras de Southey, John Armitage (1807-1856) ${ }^{21}$ e Varnhagen. Obras de outra natureza, mas de relevância histórica para o itinerário do Brasil à busca de si no século 19, incluem, dentre tantas outras, o tratado de Perdigão Malheiro sobre a escravidão ${ }^{22}$ e os 'retratos do Brasil' expressos nas inúmeras memórias e artigos do Barão do Rio Branco. ${ }^{23}$

Aos desbravadores desta quadra seguem os primeiros autores inspirados por uma preocupação analítica 'profissional', que se pode considerar como pioneiros.

${ }^{18}$ Historia Geral do Brazil, isto é, do descobrimento, colonização, legislação e desenvolvimento deste Estado. Rio de Janeiro: Laemmert, 1854.

${ }^{19}$ Francisco Iglésias. Historiadores do Brasil. Belo Horizonte/Rio: Editora da UFMG/Nova Fronteira, 2000, p.76. Esta obra de Iglésias é póstuma e sua edição foi preparada por João Antonio de Paula, professor da UFMG.

${ }^{20}$ Ibid., p. 95.

${ }^{21}$ The History of Brazil (2 vols.). Londres: Smith Elder \& Co., 1836. Imediatamente traduzido para o português: Rio de Janeiro: Villeneuve, 1837.

22 Agostinho Marques Perdigão Malheiro (1824-1881). A escravidão no Brasil (2 vols.). Rio de Janeiro: Tipografia Nacional, 1866-67.

${ }^{23}$ José Maria da Silva Paranhos Júnior (1845-1912). 


\subsection{Os pioneiros}

Os pioneiros introduzem a prática do método histórico não apenas na coleta dos dados, mas igualmente na análise e contextualização dos temas, mesmo se nem todos os aspectos são levados em conta no exame das questões. João Capistrano de Abreu é certamente o nome a ser lembrado em primeiro lugar. Representa a transição entre os coletores de dados e os analistas, parcialmente intuitivos. A esse perfil correspondem também o Sérgio Buarque de Holanda de Raízes do Brasil (1936) e o Gilberto Freyre de Casa Grande e Senzala (1933), autores que ingressam decididamente no campo historiográfico no sentido moderno, talvez até mais moderno do que certos textos recentes, pela sensibilidade interdisciplinar avant la lettre que os distinguia. São os autores que formam a prática dos 1920 a 1940, e que em parte aproveitam a inovação teórica e metodológica advinda da criação, em 1934, da Universidade de São Paulo, cuja dependência da missão francesa de intercâmbio dos anos 1930 levou, por exemplo, Paulo Eduardo Arantes a intitular Um Departamento francês de Ultramar o livro no qual trata da formação da cultura filosófica dessa universidade..$^{24} \mathrm{O}$ formato 'afrancesado' que se instala vale igualmente para a pesquisa histórica, como afirmam R. Glezer, M. H. Capelato e V. Ferlini: "O cruzamento do modo francês de fazer história, com a historiografia tradicional brasileira e com a preocupação de explicar, de forma ampla, o passado, incentivou os estudos de História Antiga, Medieval, Moderna e Contemporânea, iniciou os estudos de História da América, valorizou e redimensionou o Período Colonial, abriu novas perspectivas para a análise do Império e sedimentou a historiografia sobre o Brasil Contemporâneo. Mas, além disso, definiu uma forma de trabalho com marcas características: base erudita, rigor metodológico, coerência interna do trabalho, interdisciplinaridade e relacionamento." ${ }^{25}$ Em entrevista concedida em 1994 à revista Estudos Avançados, da USP, o historiador Fernando Novaes modula a incidência da influência francesa, apontado para o fato de o campo historiográfico, especificamente, ter já disposto de seus desbravadores. ${ }^{26}$

Entre os pioneiros contam-se profissionais que marcam com seu nome o panorama historiográfico brasileiro. No itinerário intelectual e historiográfico desses autores pode-se acompanhar a migração da formação original em Direito para a especializada em História, mesclada com certa militância na política,

\footnotetext{
${ }^{24}$ Rio de Janeiro: Paz e Terra, 1994.

${ }^{25}$ R. Glezer, M. H. Capelato, V. Ferlini. “A escola uspiana de História”. Estudos Avançados 8 (1994), p. 349-358, p. 356. CAPELATO, Maria Helena R.(org.): Produção histórica no Brasil 1985-1994. São Paulo: CNPQ/História USP/ANPUH, 1995.

${ }^{26}$ Estudos avançados 8/22 (1994); doi: 10.1590/S0103-40141994000300014.
} 
na literatura e no jornalismo. São exemplos dessa evolução Rodolfo Garcia (1873-1949), Basílio de Magalhães (1874-1957), Afonso d'Escragnolle Taunay (1876-1958), Oliveira Viana (1883-1951), Otávio Tarquínio de Souza (1889-1959), Alfredo Ellis Júnior (1896-1974), Pedro Calmon (1902-1985), Caio Prado Júnior (1907-1990), Américo Jacobina Lacombe (1909-1993), Eurípedes Simões de Paula (1910-1977), Nelson Werneck Sodré (1911-1999), Alice Canabrava (1911-2003), José Honório Rodrigues (1913-1987), Eduardo d'Oliveira França (1917-2003), dentre tantos outros. Note-se que a primeira mulher a assumir uma cátedra de História em uma universidade pública brasileira foi Alice Canabrava, em 1951, na Faculdade de Economia e Administração da Universidade de São Paulo, na área de História econômica geral e formação econômica do Brasil. ${ }^{27}$

O impulso teórico e metodológico recebido pela profissionalização dos pioneiros nas décadas de 1940 e 1950 inaugura uma nova etapa para a historiografia brasileira: a etapa os profissionais. ${ }^{28}$

\subsection{Os profissionais}

Bem entendido: os profissionais são aqui concebidos sob duas perspectivas, diversas mas complementares. A primeira é a profissionalização do ponto de vista da cientificização da História, cujos parâmetros teóricos e metódicos se instalam na prática da pesquisa e no ritmo das publicações. A segunda é a que decorre da institucionalização dos cursos de formação (bacharelado e licenciatura) e de especialização (inicialmente somente doutorados, pouco numerosos, combinados com os concursos de livre-docência e de cátedra, em seguida a distinção entre duas sucessivas fases de formação pós-graduada: mestrados e doutorados).

O padrão científico se afirma e mantém, tanto na rotina da Universidade de São Paulo quanto na Universidade do Brasil, nas respectivas faculdades de

${ }^{27}$ Flávio A. Marques de Saes. A obra de Alice Canabrava na historiografia brasileira, em http://historia_demografica.tripod.com/bhds/bhd28/fsaes-apc.pdf (acesso em 14.4.2011). Nelson Werneck Sodré. Formação histórica do Brasil. Rio de Janeiro: Civilização Brasileira, 1976, 9a ed.; História da História Nova. Petrópolis: Vozes, 1986.

${ }^{28}$ Astor A. Diehl. A matriz da cultura história brasileira: do crescente progresso otimista à crise da razão histórica - uma introdução. I. Porto Alegre: Edipucrs, 1993; A cultura historiográfica brasileira - do IHGB aos anos 1930. II. Passo Fundo: Ediupf, 1998; A cultura historiográfica brasileira - Década de 1930 aos anos 1970. III. Passo Fundo: Ediupf, 1999; A cultura historiográfica dos anos 1980: mudança estrutural na matriz historiográfica brasileira. IV. Porto Alegre: Evangraf, 1997. 
filosofia, ciências e letras. Três são os marcos distintivos em que se entrelaçam padrão e carreira: o doutoramento, a livre-docência e o concurso de cátedra. Para os que perfazem a totalidade desse percurso, tais momentos se exprimem em teses e livros que assinalam a conquista de temas e o avanço das análises. ${ }^{29}$ Os pioneiros orientam e patrocinam pesquisas que estendem notavelmente a incorporação de acervos arquivísticos e o campo de exame e crítica histórica. Discípulos de Fernand Braudel ou de Jean Gagé reúnem em torno de si novas gerações de pesquisadores, em São Paulo. História social e história econômica concentram temas e escritos. Sérgio Buarque de Holanda, catedrático de "história da civilização brasileira" a USP de 1958 a 1969, por exemplo, evidencia a persistente preocupação com o sentido da história nacional e com o horizonte para o qual sua produção se encaminha. ${ }^{30}$

Já se constata, na primeira geração de doutorados 'profissionais' produzidos na USP, entre 1951 e 1973, a abertura e a inovação temáticas. Foram defendidas 83 teses de doutorado o número é expressivo, pois em duas décadas concede-se titulação a mais profissionais do que em todo o tempo precedente. Os assuntos se enquadram ainda dentro da classificação formal clássica dos currículos universitários europeus, em especial do francês: História Antiga; História Medieval; História Moderna; História Contemporânea; História da América; História do Brasil Colônia; História do Brasil Império; História do Brasil República. ${ }^{31}$

A influência exercida pela ‘revolução historiográfica’ (Peter Burke ${ }^{32}$ ) dos Annales foi considerável na historiografia brasileira. ${ }^{33} \mathrm{Um}$ de seus elementos, a que não era estranho o conhecimento da obra de $\mathrm{Max}_{\mathrm{Weber}}{ }^{34}$, foi o recurso a

29 Ângela de Castro Gomes. História e Historiadores. Rio de Janeiro: Fundação Getúlio Vargas, 1996.

${ }^{30}$ Visão do Paraíso. Os motivos edênicos no descobrimento e colonização do Brasil. Rio de Janeiro: José Olympio, 1959. Nos anos 1960 Sérgio Buarque de Holanda organizou e coordenou a elaboração da monumental obra coletiva "História Geral da Civilização Brasileira", sucedido, após sua morte, por Boris Fausto.

${ }^{31}$ Marcos Cezar de Freitas (org.). Historiografia brasileira em perspectiva. São Paulo/ Bragança Paulista; Contexto/USF, 1998.

32 The French Historical Revolution: The Annales School, 1929-89. Stanford: Stanford University Press, 1991. Ed. brasil. São Paulo: EdUnesp, 1991.

${ }^{33}$ José Carlos Reis. Annales, a renovação da história. São Paulo: Ática, 1996; Nouvelle histoire e tempo histórico - a contribuição de Febvre, Bloch e Braudel. Ouro Preto: Edufop, 1996; Escola dos Annales. A inovação em História. São Paulo: Paz e Terra, 2000.

${ }^{34}$ Walter M. Sprondel/Constans Seyfarth (eds.). Max Weber und die Rationalisierung sozialen Handelns. Stuttgart: Enke, 1981. Ver em especial: Günther Roth. "Fernand Braudel und Max Weber. Ein strukturgeschitlicher Vergleich”, p. 59-80. 
reflexões de inspiração marxiana ${ }^{35}$ e não propriamente marxista, o que promoveu notável fertilização temática e analítica. Em diversos outros campos da reflexão histórica, notadamente na história social, na história das idéias e na história econômica os tratamentos seriais e quantitativos tiveram um momento forte até o final da década de 1980, em estudos sobretudo do comércio colonial. Os aspectos propriamente econômicos passam gradualmente a estar mais presentes no âmbito das pesquisas organizadas nos departamentos de Economia, e menos nos de História.

Outras propostas da historiografia francesa dos anos 1970, como por exemplo os trabalhos de Pierre Vilar e Albert Soboul, vieram ao encontro de preocupações presentes na sociedade brasileira, como a questão do desenvolvimento, da inserção no capitalismo e da mudança social, marcando as reflexões da passagem do Antigo Regime para a Sociedade Burguesa, vista do ângulo colonial. A idéia de revolução (burguesa) constituiu o pano de fundo de grande parte das discussões e pesquisas, refletindo leituras de Maurice Dobb, Paul Sweezy, Paul Baran, Christopher Hill, Eli Heckscher. O eixo dessa reflexão articulava, principalmente, a longa e lenta passagem do feudalismo à centralização no Antigo Regime, considerada relevante para a compreensão da natureza da colonização portuguesa (e ibérica), da sociedade por ela gerada e das formas de inserção do Brasil no sistema mundial de jaez capitalista. Nesse momento, as análises de Caio Prado Jr. constituíram referencial importante.

José Honório Rodrigues, no Rio de Janeiro, desde final dos anos 1940 sistematiza a reflexão sobre o sentido de uma História do Brasil e acerca do que se precisa conhecer para poder entendê-la e sobre ela escrever. Suas Teoria da História do Brasil e História da História do Brasil (malgrado ter ficado esta inconclusa por força de outras tarefas e afinal pelo falecimento abrupto), servem de farol de orientação para as pesquisas. ${ }^{36}$

A reflexão sobre fundamentos teóricos e procedimentos metódicos sistematizada inicialmente por José Honório Rodrigues demorará a ser retomada, pois a influência da historiografia francesa dos Annales sobre a investigação no Brasil causou uma espécie de rejeição, mesmo se inexpressa, ao esforço

${ }^{35}$ Raymond Aron. Le marxisme de Marx. Paris: Le Fallois, 2002. José Arthur Giannotti. Certa herança marxista. São Paulo: Companhia das Letras, 2000.

${ }^{36}$ Teoria da História do Brasil. $5^{\mathrm{a}}$ ed. São Paulo: Companhia Editora Nacional, 1978 (1 $1^{\mathrm{a}}$ ed., 1949; $2^{\mathrm{a}}$ ed., 1957; $3^{\mathrm{a}}$ ed., 1969; $4^{\mathrm{a}}$ ed., 1977). História da história do Brasil. Historiografia colonial. Vol. I. São Paulo: Companhia Editora Nacional; Brasília: Instituto Nacional do Livro, 1979; História da história do Brasil. A historiografia conservadora. Vol. II, t. 1 e 2. São Paulo: Companhia Editora Nacional; Brasília: Instituto Nacional do Livro, 1978-88. História combatente. Rio de Janeiro: Nova Fronteira, 1982. 
epistemológico ${ }^{37}$ Somente na década de 1950 começam a surgir as tematizações das contribuições relevantes, em torno das ideias de história-problema e de tempo como duração. ${ }^{38}$

A opção teórica pelo marxismo, aliás, também reforçou a atitude de auto-dispensa do exame teórico, dada a suposição de a filosofia marxista da História ter resolvido desta a origem, o desenvolvimento e o sentido. A questão não fica resolvida com tais opções, na medida em que a diversificação dos temas, dos objetos e dos problemas aumenta. As assim chamadas versões "simplistas", de que origem possam ser, começam a ser consideradas insuficientes para dar conta dos desafios crescentes da historiografia comparada e comparativa. Ch.-V. Langlois e Ch. Seignobos, com seu manual clássico de estudos históricos, Henri-Irenée Marrou, G. Plekhanov e tantos outros, rapidamente traduzidos para o português no Brasil, passam a um plano relativamente secundário. Note-se que Ranke teve sua primeira edição no Brasil (textos selecionados), por iniciativa de Sérgio Buarque de Holanda, somente em 1979, na coleção "Os grandes cientistas sociais". 39

\subsubsection{A expansão do campo historiográfico: etapas e temas}

A reflexão teórica e metodológica sobre a historiografia ganha novo fôlego a partir dos anos 1980, com o crescimento acelerado dos programas de pós-graduação em História (mestrados e doutorados), que requeriam capacitação qualitativamente sólida dos pesquisadores em formação. ${ }^{40}$ Passam a ser publicadas coletâneas de textos clássicos da epistemologia da História raramente

${ }^{37}$ A preferência pela 'história prática', em nome de se evitar o risco especulativo de uma filosofia da história à maneira do século 19 , levou a tal timidez epistemológica. Isso não impediu o aparecimento, tardio, das coletâneas de reflexões fundantes, como Combats pour l'histoire (Paris: Armand Colin, 1952), de Lucien Febvre, precedido pelo Apologie pour l'histoire ou métier d'historien de Marc Bloch (Paris: Armand Colin, 1941/1949).

${ }^{38}$ Esse conceito se inspira da inovação (Problemgeschichte) introduzida pelos historiadores da filosofia ligados ao neokantismo na virada do século 19 para o século 20, notadamente nos desdobramentos do pensamento de W. Dilthey. Cf. L. Geldsetzer/W. Hübener/S. Haubold, "Problemgeschichte", in Historischer Wörterbuch der Philosophie (HWPh), Basileia: Schwabe, 1989, vol. 7, col. 1410-1414; H. Holzhey, "Neukantianismus", in HWPh, vol. 6, col. 747-754. O tempo como duração tornou-se um fator relevante para a reflexão a partir do pensamento de H. Bergson sobre a experiência vivida e refletida do tempo. Cf. Essai sur les données immédiates de la conscience. Paris, F. Alcan, 1889.

${ }^{39}$ São Paulo: Ática, 1979. A introdução de Sérgio Buarque de Holanda recorria a um primeiro (e pioneiro) artigo sobre Ranke, publicado na Revista de História, n. 100, em 1974.

${ }^{40}$ Carlos Fico e Ronald Polito. A História do Brasil (1980-1989). Elementos para uma avaliação historiográfica. Ouro Preto: Ufop, 1992. 
disponíveis em língua portuguesa e a abrir espaço aos "enquadramentos teóricos" que se exigia para as teses. Pode-se lembrar as teses de Maria Yedda Linhares, Francisco C. Falcon, José Roberto do Amaral Lapa, Francisco Iglésias, Fernando A. Novaes, José Jobson de Andrade Arruda, Emília Viotti da Costa, Eulália Maria Lahmeyer Lobo, dentre outros. Esses enquadramentos, como é de praxe, vêm acompanhados das 'revisões historiográficas', em que o objeto da tese é discutido à luz da bibliografia pertinente disponível. As teses de doutoramento (como as dissertações de mestrado) contribuíram, em ritmo crescente, para o retorno do interesse pela arquitetura conceitual e pela prática metódica na elaboração dos projetos de pesquisa e da historiografia resultante.

A profissionalização (teórico-metódica) do oficio de historiador recebeu um impulso notável com a expansão dos programas de pós-graduação. Essa expansão obedeceu a três critérios principais: a qualidade científica da capacitação dos recursos humanos para a pesquisa e para a formação superior, o desenvolvimento de áreas de conhecimento estratégicas para o desenvolvimento social e econômico do país, a obtenção de autonomia científica das instituições de pesquisa e ensino no país. O primeiro plano cobriu o quinquênio 1975-1979. O segundo cobriu um quadriênio, de 1982 a 1985 . O terceiro se estendeu, por novo quadriênio, de 1986 a 1989. O quarto plano somente veio a ser organizado e posto em prática no qüinquiênio 2005-2010. O período entre 1990 e 2004, por motivos políticos e econômicos concentrou os esforços do país no controle da inflação e nas reformas da economia. Em 2010 foi iniciado o processo de elaboração do quinto plano, projetado para 2011-2015. A menção a esses planos se faz necessária porque representam a expressão de uma política pública de fomento que tornou viável o desenvolvimento, a consolidação e a expansão de inúmeras áreas de conhecimento. Inclui-se entre elas o campo historiográfico.

Entre 1970 e 2010 o crescimento das oportunidades de formação avançada em pesquisa foi exponencial: em 2011 estão em funcionamento no país 58 programas de pós-graduação em História, 30 dos quais oferecem as possibilidades de obtenção dos graus de mestre e doutor, 27 oferecem o mestrado acadêmico e um o mestrado profissionalizante. ${ }^{41} \mathrm{O}$ duração habitual dessas formações é de dois anos para o mestrado e de quatro anos para o doutoramento. Um dos fatores que propiciaram o avanço e a diversificação dos objetos históricos estudados

${ }^{41}$ A expressão "mestrado profissionalizante" é utilizada para a formação em nível pós-graduado com duração e requisitos próprios, voltada para o exercício profissional em determinada área específica. No caso referido, trata-se da área de preservação do patrimônio histórico, promovido pela Fundação Getúlio Vargas, no Rio de Janeiro. 
é a organização dos programas em áreas de concentração, que se estruturam em linhas de pesquisa. Estas agregam os projetos de pesquisa em andamento.

No retrato atual que fornecem as áreas de concentração, o tema da sociedade e da cultura, com seus componentes de construção, administração e reprodução das identidades macro-, meso- e microssociais, serve de referência organizadora da sistematização da investigação e da narrativa historiográfica no Brasil. ${ }^{42}$ Dos 58 programas em funcionamento, vinte e cinco utilizam a referência à sociedade e aos movimentos sociais como modo de caracterizar sua forma de lidar com a memória e a narrativa. Dezoito recorrem à cultura e suas variantes como eixo articulador. Por certo há referências cruzadas, em que história social e história cultural se imbricam. Três outras variáveis se juntam ao quadro genérico de cultura e sociedade: relações de poder; território, região e fronteiras; estado, poder, política e instituições. Alguns temas de relevância regional também permitem aprofundar questões de interesse local, em perspectiva comparada nacional e internacional, como a história social da Amazônia ou do Norte e Nordeste do Brasil. Encontra-se também representada a preocupação crítica de contextualização de tempos e espaços de longo prazo, com a história ibérica e latino-americana ${ }^{43}$ No caso da América Latina, houve um crescimento da integração temática das questões transfronteiriças e territoriais, notadamente no Cone Sul (Argentina, Brasil, Chile, Paraguai, Uruguai) e no centro-oeste sul-americano (Bolívia, Colômbia, Peru).

A propósito dessa evolução historiográfica, cabe fazer aqui menção ao surgimento e rápido desenvolvimento do campo das Relações Internacionais no Brasil, relevante para o surgimento e o estabelecimento de pesquisa históricas em perspectiva trans- e supranacional. O Brasil integra a rede mundial de polos de investigação e formação em relações internacionais, na qual alcançou posição de destaque. Inicialmente voltado para os estudos da política externa do país, o campo abriu o leque e tornou-se referência na fundamentação teórica e na diversidade temática em relações internacionais. O momento inaugural foi a criação do Instituto Brasileiro de Relações Internacionais (IBRI), no Rio de Janeiro, em 1954 (em Brasília desde 1993; edita a Revista Brasileira de Política Internacional - RBPI); segue-se o curso de graduação em relações internacionais - o primeiro do país - na Universidade de Brasília, em 1974,

${ }^{42}$ Estevão de Rezende Martins. "Cultura, multiculturalismo e os desafios da compreensão histórica." Textos de História, Brasília, 10 (2004), p. 225-230; "Pensamento histórico, cultura e identidade.", id., p. 215-219.

${ }^{43}$ E. de Rezende Martins;H. Pérez-Brignoli (eds.). Teoría y metodología en la Historia de América Latina. Madri: Editorial Trotta - Ediciones Unesco, 2006. 
e o programa de pós-graduação em História das Relações Internacionais no Departamento de História, em 1976 (a partir de 2002 no Instituto de Relações Internacionais da mesma Universidade). A contribuição reflexiva do pensamento brasileiro em RI, metodicamente articulado com especialistas argentinos, põe em relevo a originalidade da perspectiva de análise fora e para além das assim chamadas escolas inglesa, francesa ou americana, e em diálogo com elas.

A renovação metódica e a inovação temática da pesquisa em história das relações internacionais na região se deram do Departamento de História da Universidade de Brasília e no Instituto de Investigaciones de Historia Econômica y Social da Universidade de Buenos Aires, cujos trabalhos marcam o desenvolvimento da área desde a década de 1980. A perspectiva latino-americana de uma autonomia reflexiva sustentou a transformação de métodos e teorias na abordagem das questões internacionais, para fora e para além dos paradigmas prevalentes no hemisfério norte. Notadamente os temas da segurança e dos conflitos armados deixaram a linha de frente, dada a tradição regional entrementes pacificada, embora a questão da segurança hemisférica volte mais tarde, a partir dos anos 2000, a integrar a agenda estratégica. Ganharam em importância os problemas ligados ao desenvolvimento e à autonomia econômica e financeira. $\mathrm{O}$ argumento dos pesquisadores latino-americanos recorre à constatação de que o tema do desenvolvimento foi uma constante das políticas externas das potências desde os anos 1930.

A interlocução interdisciplinar cresce acentuadamente. Tal contribui para que áreas de pesquisa e ensino em História se dediquem também à história econômica (o único curso de pós-graduação formalmente com essa área em História, está na Universidade de São Paulo, em estreita cooperação com a Cátedra Jaime Cortesão, aí sediada), à história das ciências, à história do tempo presente, à história comparada.

As linhas de pesquisa e os projetos desenvolvidos obviamente desdobram o leque, mais restrito e genérico, das áreas de concentração. Uma das linhas de pesquisa mais produtivas e desenvolvidas é a que se ocupa das raízes do Brasil. O desafio posto por Sérgio Buarque de Holanda suscitou e suscita um sem número de aprofundamentos da história do Brasil colonial, de sua excepcionalidade monárquica no século 19 , de sua modernização almejada e trôpega no século $20 .{ }^{44}$

$\mathrm{O}$ manancial do temas ligados à africanidade brasileira, com suas redes de comunicação e interdependência no Atlântico Sul, impulsionaram notavelmente

${ }^{44}$ Pesavento, Sandra J. (ed.) Um historiador nas fronteiras: o Brasil de Sérgio Buarque de Holanda. Belo Horizonte/São Paulo: Ed. UFMG/Humanitas, 2005. 
os estudos - de grande fôlego - ligados à escravidão e a seus desdobramentos até os dias de hoje. A história social, cultural, política e econômica da escravidão e de suas variáveis é um tema recorrente e em expansão - o entendimento da brasilidade, sustenta a historiografia, passa forçosamente pela compreensão da africanidade transposta. Um de seus desdobramentos relevantes é a introdução da obrigatoriedade do ensino de história da África no ensino fundamental e médio brasileiro.

O tema da diversidade étnica na composição da sociedade brasileira é objeto de imposição legal e de indução por política pública. ${ }^{45} \mathrm{~A}$ prevalência de temas de cunho europeu é tradicional e inercial ${ }^{46} \mathrm{~A}$ vertente afro-brasileira está em pleno e justificado desenvolvimento, longamente esperado. A perspectiva indígena, predominantemente tratada pela antropologia, começa a ser levada em conta nas pesquisas de cunho histórico, pelo diálogo interdisciplinar, pela criação de programas de pesquisa e pós-graduação em regiões em que há forte componente indígena no perfil sócio-demográfico (especialmente nas regiões Norte e Centro-Oeste) e pela assunção do tema em demais setores.

A história política da gestão colonial portuguesa e de seus efeitos na conformação da sociedade, da cultura, da economia e da política brasileiras fez levar adiante o procedimento da apropriação das fontes europeias (notadamente portuguesas e espanholas) e de sua análise detida. ${ }^{47} \mathrm{O}$ incremento notável da circulação de pesquisadores, mediante programas de financiamento público de bolsas de formação doutoral no exterior (em tempo integral ou na modalidade "sanduíche", em que o candidato começa e conclui no Brasil, passando em

${ }^{45}$ Constituição da República Federativa do Brasil: art. 242, $\$ 1^{\circ}$ O ensino da História do Brasil levará em conta as contribuições das diferentes culturas e etnias para a formação do povo brasileiro. Lei de Diretrizes e Bases da Educação Nacional (9.394/1996): art. 26, § $4^{\circ}$ O ensino da História do Brasil levará em conta as contribuições das diferentes etnias para a formação do povo brasileiro, especialmente das matrizes indígena, africana e européia. Esta lei ganhou um artigo em 2003, pela Lei 10.639: art.26-A Nos estabelecimentos de ensino fundamental e médio, oficiais e particulares, torna-se obrigatório o ensino sobre História e Cultura Afro-Brasileira. $\S 1^{\circ}$ O conteúdo programático a que se refere o caput deste artigo incluirá o estudo da História da África e dos Africanos, a luta dos negros no Brasil, a cultura negra brasileira e o negro na formação da sociedade nacional, resgatando a contribuição do povo negro nas áreas social, econômica e política pertinentes à História do Brasil. $\$ 2^{\circ}$ Os conteúdos referentes à História e Cultura Afro-Brasileira serão ministrados no âmbito de todo o currículo escolar, em especial nas áreas de Educação Artística e de Literatura e História Brasileiras.

46 José Ricardo Oriá Fernandes. "Ensino de história e diversidade cultural: desafios e possibilidades.” Cad. Cedes, Campinas, 25 (2005) p. 378-388.

${ }^{47}$ Passo importante dessa estratégia de pesquisa histórica foi o Projeto Resgate, acordo passado em 1995 entre o Brasil (Ministério da Cultura) e Portugal (Arquivo Histórico Ultramarino) para a digitalização dos documentos relativos ao Brasil. Ver, por exemplo, www.resgate.unb.br 
torno de um ano em instituição estrangeira), alargou o espectro de critérios e de referências, permitiu aumentar sensivelmente o estoque de fontes e de comparação historiográfica internacional. ${ }^{48}$

\subsubsection{A expansão do campo historiográfico: publicações e associações}

A vitalidade da historiografia aparece na qualidade e no volume das publicações. A quantidade de monografias e de periódicos em História no Brasil cresce regularmente, diversifica suas áreas de interesse e multiplica seu público. ${ }^{49}$

Os marcos iniciais da etapa profissionalizante estão na fundação em 1950, por Eurípides Simões de Paula, da Revista de História, ainda hoje sediada na Universidade de São Paulo, e na fundação, em 1961, da Associação Nacional dos Professores Universitários de História (ANPUH), que abreviou seu nome para Associação Nacional de História em 1993, mantida a sigla (www.anpuh.org). Essas iniciativas registram a fase de passagem do pioneirismo ao profissionalismo. A Associação Nacional de História está organizada em 24 das 27 unidades da federação brasileira, o que reflete a expansão e o alcance da formação e da pesquisa em História. A cada biênio a Anpuh organiza um simpósio nacional em que são discutidos e analisados os últimos avanços nacionais e internacionais da historiografia. ${ }^{50}$ As seções regionais organizam pelo menos a cada dois anos simpósios regionais. A quase totalidade desses simpósios gera publicações historiográficas importantes, sob a forma de livros ou de dossiês temáticos em periódicos especializados. A Anpuh reúne igualmente banco de dados sobre as áreas de pesquisa e publicação em historiografia no Brasil, sob a denominação de "Quem é quem na História?" - um instrumento valioso para um perfil atualizado da dinâmica crescente do campo.

A Revista de História sediada na USP teve uma longa interrupção entre 1977 e 1983, tendo sido retomada desde então. Nesse meio tempo a Anpuh entendeu que a comunidade epistêmica dos historiadores necessitava de um periódico acadêmico nacional. Foi assim fundada, em 1981, a Revista Brasileira de História, publicada ininterruptamente. Em julho de 2003, com a difusão

${ }^{48}$ A título de exemplo: o Conselho Nacional de Desenvolvimento Científico e Tecnológico (CNPq), em 1951, havia financiado 48 bolsas. Em 2009 (últimos dados consolidados), foram 69.190, 579 das quais no exterior. A grande área de Ciências Humanas, em que está incluída a História, recebeu 7.614 bolsas no país, 64 no exterior (para todas as modalidades). A Fundação CAPES, em 2009, distribui 8.253 bolsas nessa área, 697 das quais no exterior.

49 A revista histórica mais antiga do país é a Revista do Instituto Histórico e Geográfico Brasileiro, em circulação desde 1839 (http://www.ihgb.org.br/rihgb.php).

${ }^{50}$ Em 2011 realiza-se o $26^{\circ}$ simpósio, sob o título "Anpuh 50 Anos: Comemorações". 
acadêmica da formação em História, a Anpuh criou uma revista eletrônica destinada a versar sobre temas atuais e experiência de ensino de História (Revista História hoje).$^{51}$ As publicações periódicas receberam um impulso qualitativo substancial, na medida em que o sistema nacional de avaliação de desempenho acadêmico (integrado pelas comunidades acadêmicas e gerido pela Fundação Capes), no Brasil, instituiu e passou a aplicar critérios de ponderação qualitativa (conhecido como "Qualis" ${ }^{52}$ ). A plataforma eletrônica facilitou a difusão e o alcance das publicações, além de baratear-lhes os custos: vinte e três revistas eletrônicas estão disponíveis aos pesquisadores. ${ }^{53}$

No âmbito da Anpuh e de associações análogas formaram-se grupos de trabalho temáticos, que congregam pesquisadores por área afim e de forma interinstitucional. O desenvolvimento desses grupos ensejou a fundação de diversas sociedades especializadas, como a Sociedade Brasileira de Pesquisa Histórica (1981), Sociedade Brasileira de História da Ciência (1983), Associação Brasileira de Pesquisadores em História Econômica (1993), Associação Nacional de Pesquisadores de História Latino-Americana e Caribenha (1993), Associação Brasileira de História Oral (1994), Associação Brasileira de Estudos Medievais (1996), Associação Brasileira de História das Religiões (1999), Associação Brasileira de Ensino de História (2008), Sociedade Brasileira de Teoria e História da Historiografia (2009) - a lista é grande e não exaustiva. Tem o mérito de colocar em evidência três aspectos: o crescimento das respectivas áreas de conhecimento, a densidade dos grupos de pesquisadores a elas associados, a vontade de congregar e institucionalizar em sociedades científicas especializadas.

A densidade da produção historiográfica desde a década de 1980 se refletiu igualmente no aumento significativo da publicação de livros monográficos, principalmente acerca de temas relevantes sobretudo para a história brasileira. Esse movimento colocou a questão histórica no espaço público de modo

${ }^{51}$ Cf. M. A. Schmidt; Isabel Barca; E. de Rezende Martins (eds.). Jörn Rüsen e o ensino de História. Curitiba/Braga: Editora UFPR - Universidade do Minho, 2010.

$52 \mathrm{http} / /$ qualis.capes.gov.br/webqualis/.

${ }^{53}$ Destacam-se entre elas: Fênix - Revista de História e Estudos Culturais (www.revistafenix. pro.br); ArtCultura: Revista de História, Cultura e Arte (www.artcultura.inhis.ufu.br/); História Agora - Revista de História do Tempo Presente (www.historiagora.com); História da Historiografia (www.ichs.ufop.br:80/rhh); Antíteses (www.uel.br/revistas/uel/index.php/antiteses); Revista Eletrônica de História Antiga e Medieval (www.revistamirabilia.com); Revista Eletrônica de História Comparada (www.grupos.com.br/group/comparada/); Revista Urbana - Periódico do Centro Interdisciplinar de Estudos da Cidade - CIEC/Unicamp (www.ifch.unicamp.br/ciec/ revista/index.php); Tempo e Argumento (www.periodicos.udesc.br/index.php/tempo/index); Territórios e Fronteiras (www.cpd1.ufmt.br/ichs/territorios\&fronteiras). 
muito mais amplo, para além dos círculos dos pesquisadores universitários e dos vinculados ao ensino de História no sistema escolar. Temas e personagens históricos passaram igualmente a ser objeto de escritores de fora do mundo historiográfico formal, em particular de jornalistas, cujos livros alcançaram penetração na sociedade. ${ }^{54}$

$\mathrm{Na}$ interface de difusão do conhecimento historiográfico cientificamente construído para a sociedade em geral, destaca-se a criação, em 2005, da Revista de História da Biblioteca Nacional, de periodicidade mensal, que obteve rápida aceitação do público em geral. ${ }^{55}$ Esta revista prima por transpor para uma linguagem socialmente didática conteúdos apresentados e discutidos por profissionais reconhecidos de História. Sua inspiração é a revista francesa L'Histoire, fundada em $1978 .{ }^{56}$ Note-se ademais que as revistas de divulgação de conteúdo histórico, também fortemente calcadas nos exemplos franceses, têm alcançado sucesso de público, notadamente por serem vendidas em bancas de jornais. ${ }^{57}$ Esse sucesso se explica possivelmente por dois fatores: de uma parte, a presença mais forte do produto historiográfico no espaço social; de outra parte, pela elevação do nível cultural da sociedade, que passa a interessar-se pelas questões do tempo e do espaço passados do mundo experimentado no presente e de suas perspectivas de futuro.

Presente na vida social como um todo, a reflexão histórica ingressou firmemente na consciência histórica e na cultura, como elemento de constituição do pensamento histórico, de formação das identidades em todos os níveis e como fórum de encontro dos agentes individuais e coletivos.

Recebido em/Text submitted on: 29/04/2011

Aceite em/Approved on: 13/06/2011

${ }^{54}$ Por exemplo: Eduardo Bueno, Elio Gaspari, Fernando Moraes, Laurentino Gomes, dentre outros. A obra desses autores é objeto de reações controversas: criticados por se aventurarem pelas sendas da História sem serem historiadores, elogiados por abrirem as sendas da História justamente aos que não são historiadores.

$55 \mathrm{http}: / / \mathrm{www} \cdot$ revistadehistoria.com.br.

${ }^{56} \mathrm{http}: / /$ www.histoire.presse.fr.

${ }^{57}$ Duas das mais difundidas são História Viva (2003) e Aventuras na História (2003). 